\title{
New Herpetofaunal Records for Great Isaac Cay, Bimini Group, Bahamas
}

\author{
Kristin M. Winchell ${ }^{1}$, Pavitra Muralidhar ${ }^{2}$, Jason R. Fredette ${ }^{1}$, and R. Graham Reynolds ${ }^{2}$ \\ ${ }^{1}$ University of Massachusetts Boston, Boston, Massachusetts (kristin.winchell001@umb.edu) \\ ${ }^{2}$ Museum of Comparative Zoology \& Department of Organismic and Evolutionary Biology, Harvard University, Cambridge, Massachusetts \\ Photographs by the senior author.
}

\begin{abstract}
$\mathrm{M}$ any of the $-3,100$ islands, cays, and rocks that comprise the Bahamian Archipelago are low-lying and isolated. Understandably, the presence of herpetofauna on some of these isolated islands remains undocumented, despite extensive compilations (MacLean et al. 1977; Buckner et al. 2012). During fieldwork in the western Bahamas in the spring of 2015, we had the opportunity to conduct a diurnal herpetofaunal survey on one of these isolated islands: Great Isaac Cay, Bimini Group, Bahamas (latitude 26.034046, longitude -79.099485; Figs. $1 \& 2$ ). Great Isaac is a small (approximately $420 \times 30 \mathrm{~m}$ ) island located $40 \mathrm{~km}$ north of Alice Town, Bimini, on the extreme northwestern corner of the Great Bahama Bank. Deep channels of water separate this bank from Florida (Florida Strait) and the northern Bahamian islands (Northwest Providence Channel; Fig. 2). The island was historically home to an actively staffed lighthouse originally constructed in 1856 (Fig. 3). Now only ruins remain and the lighthouse has been automated since the last lighthouse keepers (apparently) disappeared in 1969. The island currently is frequented only by daytime visitors looking to explore the ruins and Bahamian commercial fishermen who occasionally use the structures for shelter.
\end{abstract}

No beaches provide easy points of access to Great Isaac Cay. Our skilled captain maneuvered the boat next to the jagged and steep rocky edge of the island (Fig. 4a) so that our field team could climb ashore, and departure required swimming back to the boat. The island is composed of oolitic and limestone deposits. The rocky terrain was sharp and difficult to traverse where vegetative litter and sand had not accumulated. The island was dominated by two types of vegetation, cacti and Casuarina, the latter an invasive tree native to Australia. A large, well-developed stand of Casuarina trees (Fig. 4b) lies at the eastern end of the island. The leaf litter in this area was $50-150 \mathrm{~mm}$ deep and was composed almost entirely of Casuarina twigs on a bed of sand. No canopy existed outside of this area and the island was exposed to full sun (Fig. 4c). At least half of the island is exposed karst with little or no vegetation. The island rises no more than $15-20 \mathrm{~m}$ above sea level at its highest points and possibly is swept over by waves during large storms. The island is polluted with substantial amounts of plastic debris (both washed ashore and discarded) and dozens of discarded lead acid batteries, which have been intentionally dumped near the ruins of the lighthouse.

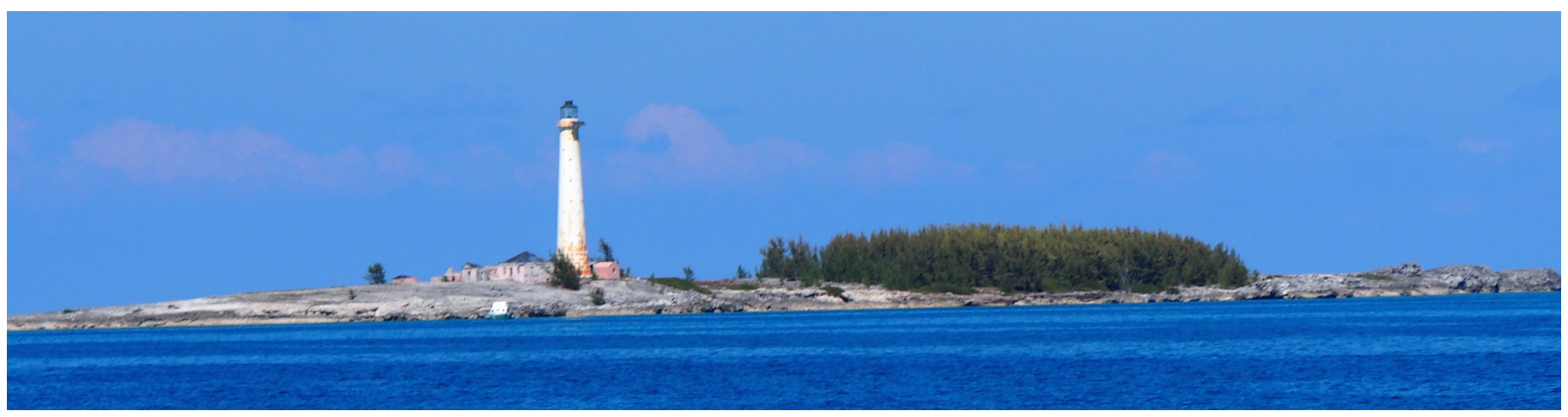

Fig. 1. Great Isaac Cay as approached from the south, with the abandoned lighthouse and support buildings on the western end and mature Casuarina forest on the center and eastern end of the island. 


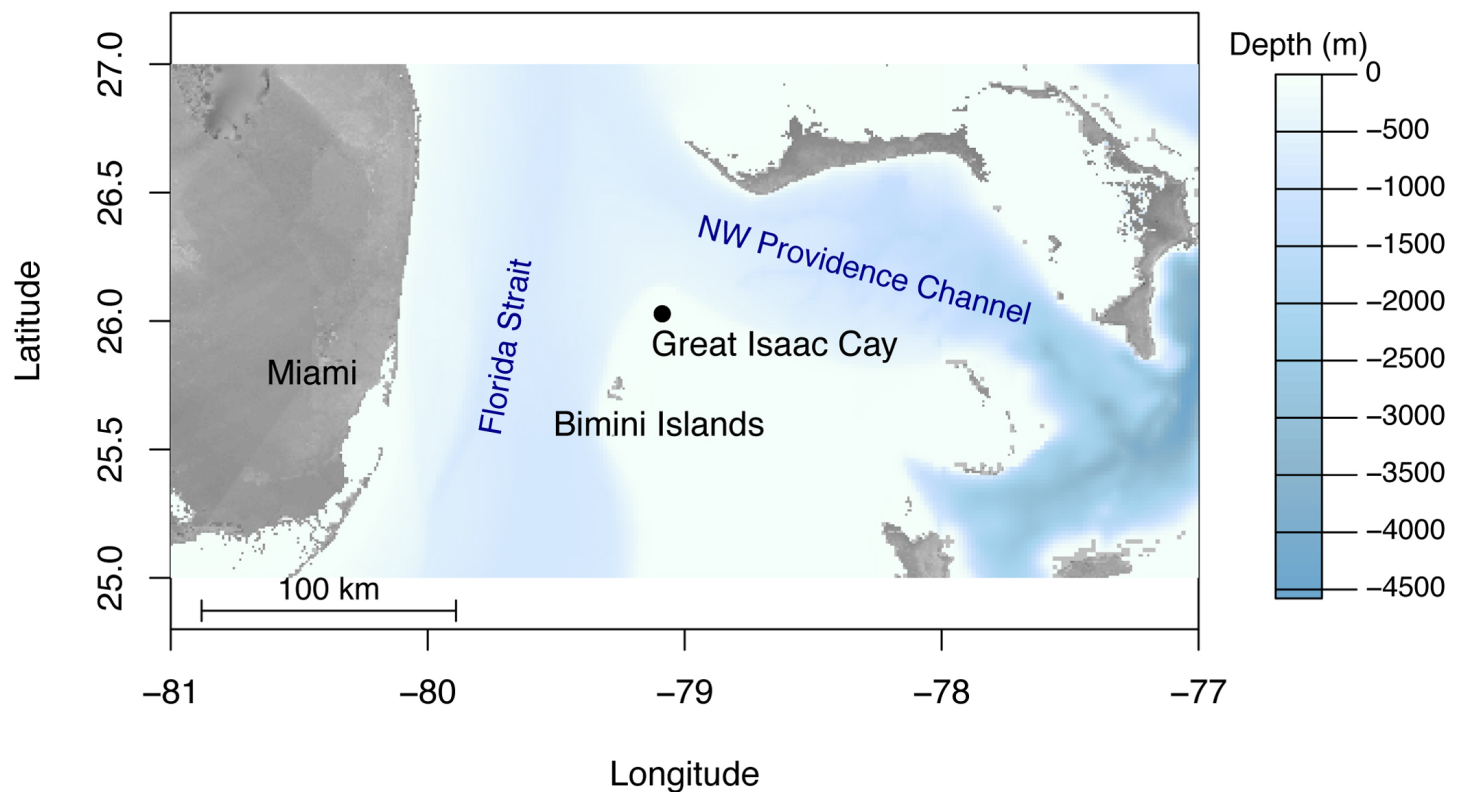

Fig. 2. Map of the northwestern Bahamas showing the isolated location of Great Isaac Cay.

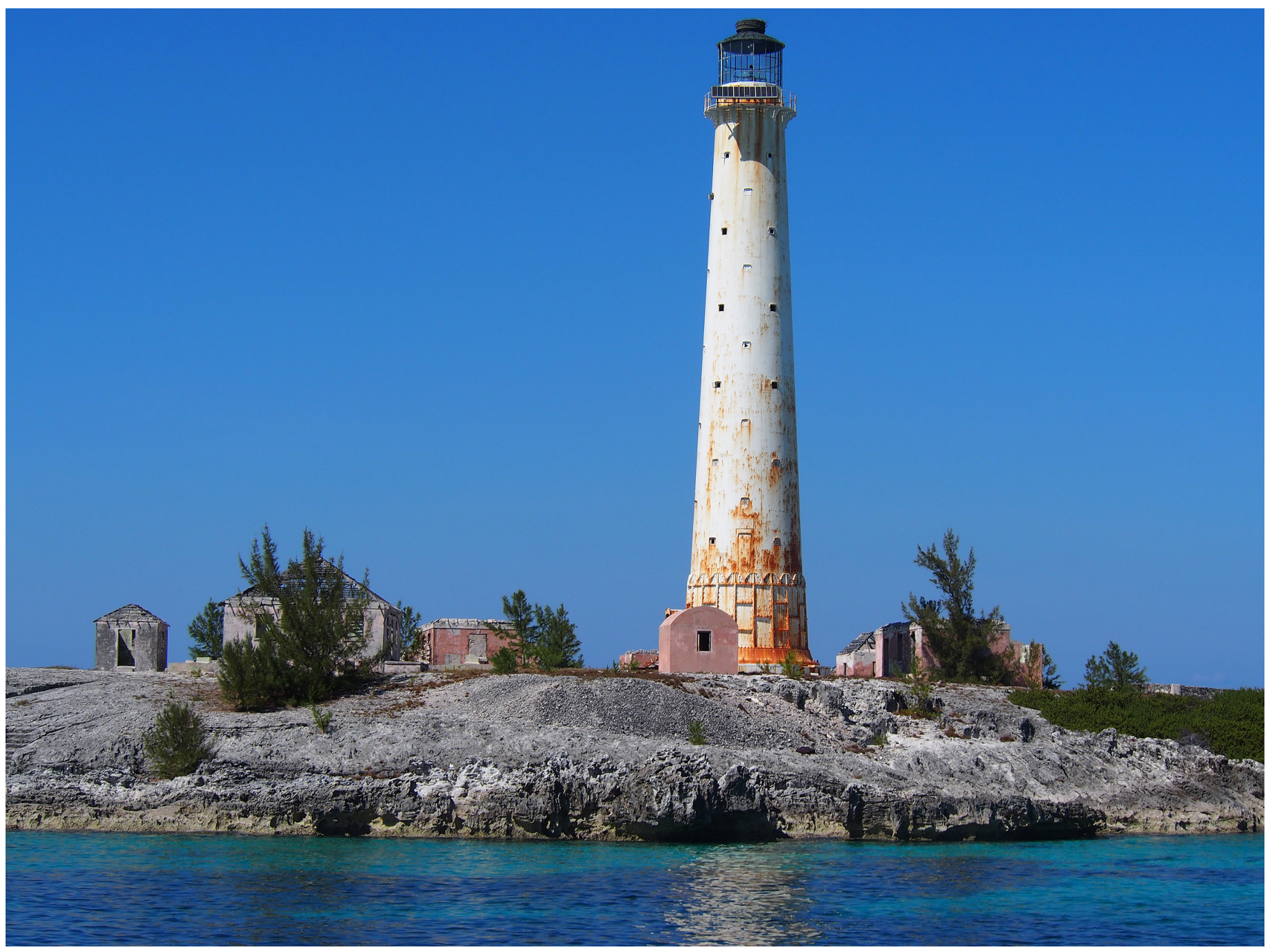

Fig. 3. The lighthouse and associated ruins on Great Isaac Cay. 


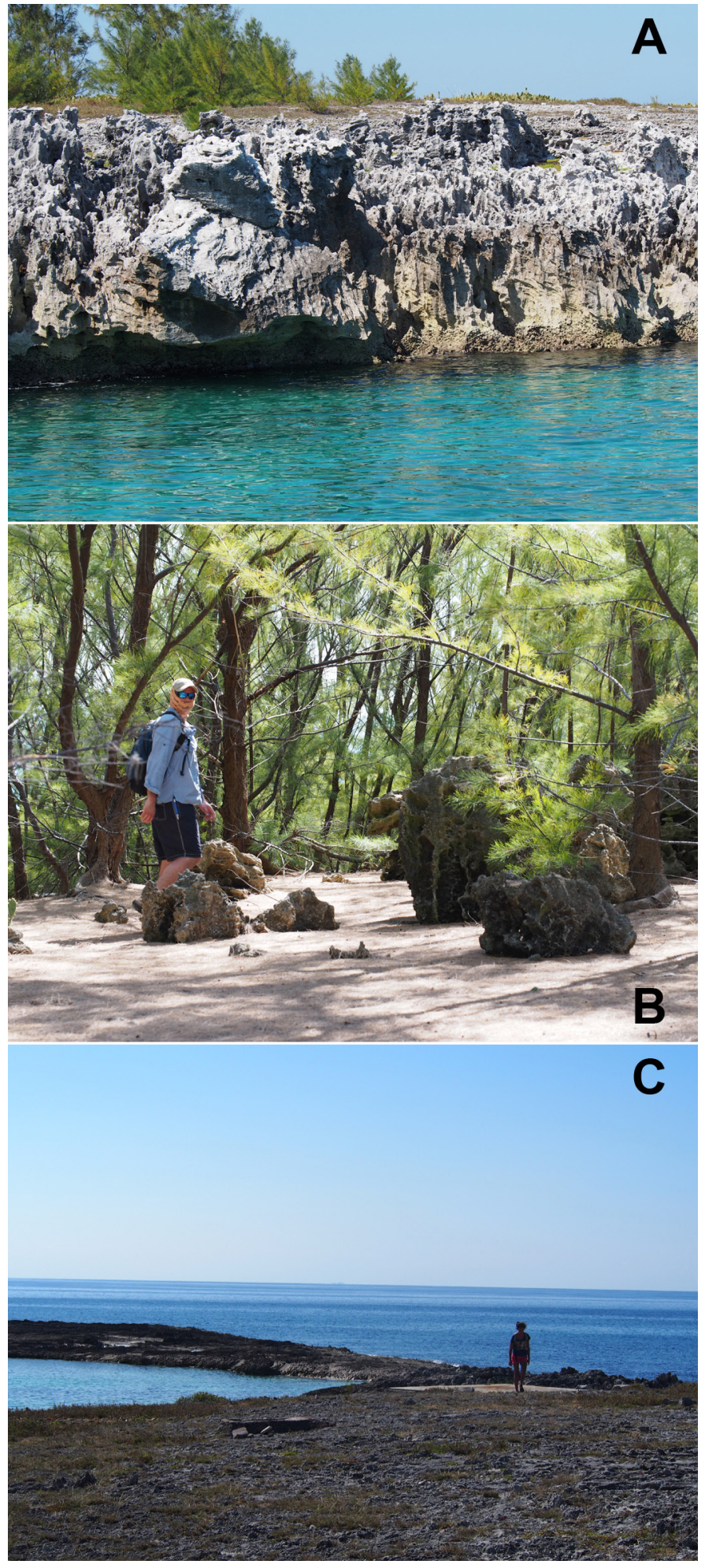

Fig. 4. (A) The rocky coast of Great Isaac Cay with young Casuarina on the left and cacti on the right. (B) RGR in the Casuarina stand. (C) The western end of the island is completely exposed with little vegetation.

Despite the abundant vegetation, we were surprised to find very few reptiles on Great Isaac Cay. Four of us spent approximately six person-hours around $1500 \mathrm{~h}$ searching for herpetofauna. This was ample time to explore the entire island. We surveyed for reptiles by checking on and around the Casuarina trees, bushes, and buildings, and by lifting and replacing loose rocks. We encountered over a dozen male and female Black-spotted Dwarf Geckos (Sphaerodactylus nigropunctatus flavicauda) under rocks in the Casuarina stand (Fig. 5) and two Cuban Ameivas (Ameiva auberi richmondi) in the open area around the buildings. We found no other reptiles, including anoles, which generally are ubiquitous even on small Bahamian islands (e.g., Schoener et al. 2001). We were unable to locate any other records for herpetofauna on Great Isaac Cay. The island was originally listed in the Bahamian herpetofaunal lists without any species records (MacLean et al. 1977), and hence was not even included in the most recent lists (Buckner et al. 2012).

The herpetofaunal community of Great Isaac Cay is intriguing because the island has likely been subject to periodic natural disturbance as well as ongoing human disturbance. During significant storms and hurricanes, the island would be subject to high winds and potentially inundating storm surges. Such disturbances can completely clear low-lying exposed islands of resident vertebrates and invertebrates with effects lasting a year or longer (Spiller et al. 1998; Schoener et al. 2001). These effects might be particularly strong on Great Isaac Cay owing to its location at the edge of the Great Bahama Bank and greater exposure to nearby deeper ocean waters in the Florida Strait and the Northwest Providence Channel. Casuarina, the dominant vegetation on Great Isaac Cay, is a shallow rooter and also can be completely removed from the island by high winds and storm surges during large periodic storms (Morton 1990). Because of the island's isolation, frequent natural recolonization from nearby islands (the closest of which is $30 \mathrm{~km}$ away) is unlikely and species persistence likely relies on the ability to withstand large natural disturbances or "sweepstakes" dispersals. The two herpetofaunal species we encountered are semi-fossorial, which might indicate that their ability to utilize subterranean refugia buffers them from the effects of storms. In contrast, anoles would have to weather high winds and flooding in the trees on such a small island. In addition, Sphaerodactylus geckos might be better adapted for overwater dispersal as their eggs are somewhat tolerant of saltwater immersion and dehydration (Brown and Alcala 1957) and their toepads enable them to grip strongly to floating vegetation (Russell 2002; Vanhooydonck et al. 2005).

The century-long inhabitation of the island by the lighthouse keepers and staff likely has impacted the flora and fauna of the island as well. Lighthouse keepers have been documented to dramatically influence vertebrate fauna on small islands indirectly through the introduction of companion animals (e.g., Medway 2004). Human activities might have either impeded or facilitated the persistence or colonization of herpetofauna. The dominant plant, Casuarina, is native to Australia and was introduced widely throughout the Caribbean in the 1800 s for shade and windbreaks. These hardy trees are tolerant of salt and drought and grow at a rapid pace, often displacing 


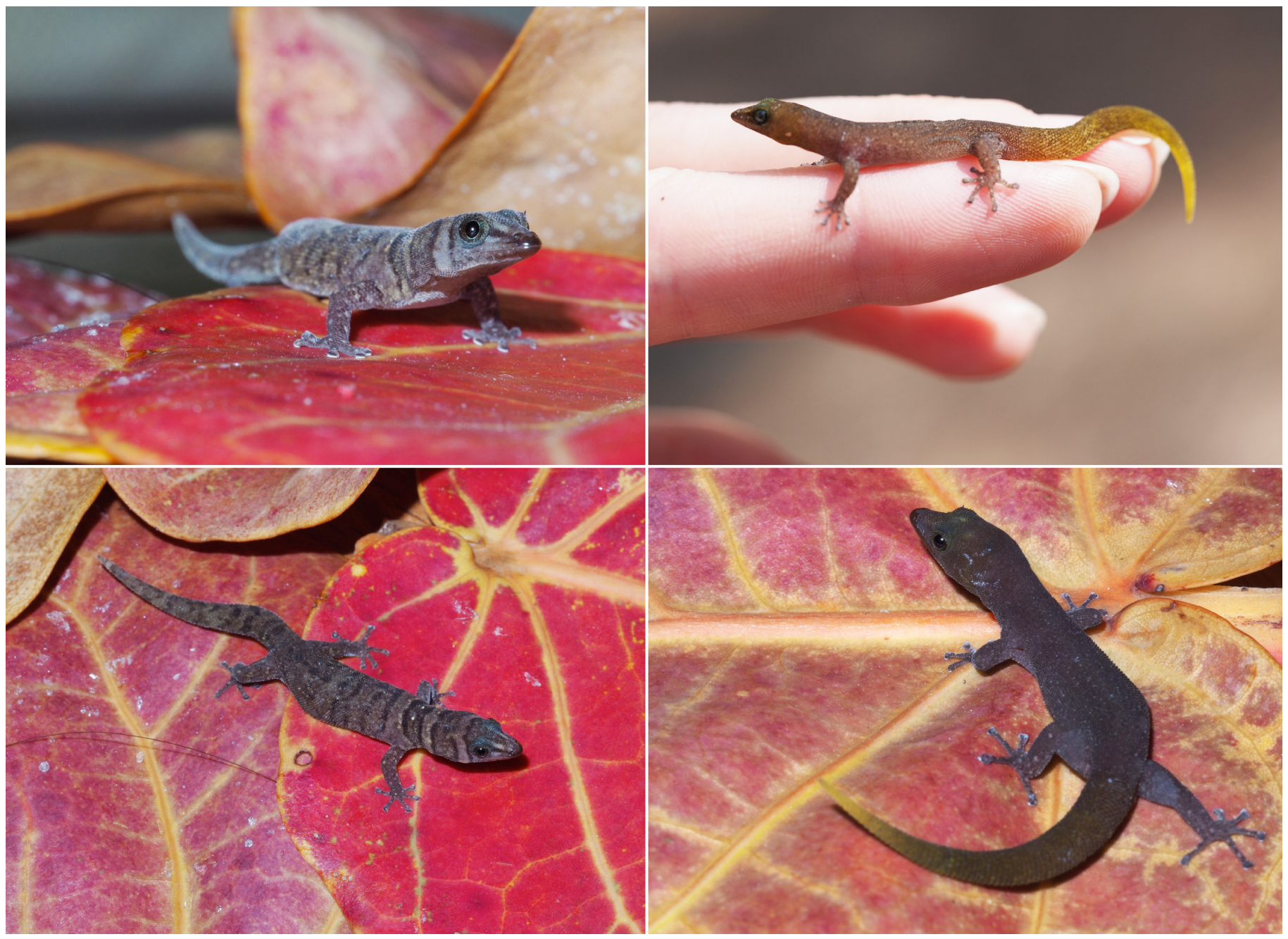

Fig. 5. Black-spotted Dwarf Gecko (Sphaerodactylus nigropunctatus flavicauda). Left panels: females; right panels: males.

native flora (Morton 1990). While we do not know about the historic state of the island's flora, the development of this forest likely altered the thermal habitat (by creating canopy cover) and provided structural habitat necessary for the persistence of certain species while possibly outcompeting native flora beneficial to others. This habitat also might have functioned to shelter fauna from frequent storms that otherwise might have wiped an un-vegetated island clean. Additionally, human presence might have enabled the colonization and persistence of certain reptiles. Small reptiles could have been transported in shipments of materials to the island, resulting in humanmediated introductions more frequent than naturally occurring dispersal. The construction of buildings would have provided additional shelter, and food waste may have supported insect communities in greater abundance than would otherwise have occupied such a small island. This phenomenon has been observed in urban areas, where buildings can provide novel refuges and artificial lights and food waste support large numbers of insects on which herpetofauna feed (e.g., Perry et al. 1998; Henderson and Powell 2001).
Our brief survey documents for the first time the presence of two reptilian species, Sphaerodactylus nigropunctatus flavicauda and Ameiva auberi richmondi, on Great Isaac Cay in the Bahamas. It also draws attention to the potential difficulties of colonization and persistence on such low-lying, exposed, heavily modified, and isolated islands in this region. Many islands of similar size and isolation remain unexplored and their herpetofaunal communities undocumented. In the most recent Island List of West Indian Amphibians and Reptiles, Buckner et al. (2012) listed species records for only 297 islands in the Bahamian Archipelago. Additional surveys of this nature could yield interesting information for future studies and should be encouraged.

\section{Acknowledgements}

We thank Ken and Pauline Rorabaugh, who offered their vessel for transport to Great Isaac Cay. We also acknowledge support from Jonathan B. Losos and the Museum of Comparative Zoology at Harvard. 


\section{Literature Cited}

Brown, W.C. and A.C. Alcala. 1957. Viability of lizard eggs exposed to sea water. Copeia 1957:39-41.

Buckner, S.D., R. Franz, and R.G. Reynolds. 2012. Bahama Islands and Turks and Caicos Islands, pp. 93-112. In: R. Powell and R.W. Henderson (eds.), Island lists of West Indian amphibians and reptiles. Bulletin of the Florida Museum of Natural History 51:85-166.

Henderson, R.W. and R. Powell. 2001. Responses by the West Indian herpetofauna to human-influenced resources. Caribbean Journal of Science 37:41-54.

MacLean, W. P., R. Kellner, and H. Dennis. 1977. Island lists of West Indian amphibians and reptiles. Smithsonian Herpetological Information Service 40:1-47.

Medway, D.G. 2004. The land bird fauna of Stephens Island, New Zealand in the early 1890s, and the cause of its demise. Notornis 51:201-211.

Morton, J.F. 1980. The Australian Pine or Beefwood (Casuarina equisetifolia L.), an invasive "weed" tree in Florida. Proceedings of the Florida State Horticultural
Society 93:87-95.

Perry, G., B.W. Buchanan, R.N. Fisher, M. Salmon, and S.E. Wise. 2008. Effects of artificial night lighting on amphibians and reptiles in urban environments, pp. 239-256. In: J.C. Mitchell, R.E. Jung Brown, and B. Bartholomew (eds.), Urban Herpetology. Herpetological Conservation, volume 3, Society for the Study of Amphibians and Reptiles, Salt Lake City, Utah.

Russell, A.P. 2002. Integrative functional morphology of the gekkotan adhesive system (Reptilia: Gekkota). Integrative and Comparative Biology 42:1154-1163.

Spiller, D.A., J.B. Losos, and T.W. Schoener. 1998. Impact of a catastrophic hurricane on island populations. Science 281:695-697.

Schoener, T.W., D.A. Spiller, and J.B. Losos. 2001. Natural restoration of the species-area relation for a lizard after a hurricane. Science 294:1525-1528.

Vanhooydonck, B., A. Andronescu, A. Herrel, and D.A. Irschick. 2005. Effects of substrate structure on speed and acceleration capacity in climbing geckos. Biological Journal of the Linnean Society 85:385-393. 